\title{
Graphing Behaviour of Heat Transfer In Terms of Nusselt and Reynolds
}

\author{
Mohd Rahimie Md Noor ${ }^{1 *}$, Nur Syafiqah Hidayah Mohd Fauzi ${ }^{2}$, Siti Nur Fadhilah Masrom ${ }^{3}$, \\ Mohd Azry Abdul Malek ${ }^{4}$, Muhammad Firdaus Mustapha ${ }^{5}$, Ahmad Bukhari Mohd Yasin ${ }^{6}$ \\ ${ }^{1,2,3}$ Department of Mathematics, Universiti Teknologi Mara Kelantan,18500 Machang, Kelantan \\ ${ }^{4}$ Department of Statistics, Universiti Teknologi Mara Kelantan,18500 Machang, Kelantan \\ ${ }^{5}$ Department of Computer Science, Universiti Teknologi Mara Kelantan,18500 Machang, Kelantan \\ ${ }^{6}$ Department of Business, Universiti Teknologi Mara Kelantan,15050 Kota Bharu, Kelantan \\ Corresponding author: ${ }^{*}$ mohdr697@ kelantan.uitm.edu.my
}

Received Date: 18 April 2021

Accepted Date: 5 June 2021

Published Date: 1 September 2021

\section{HIGHLIGHTS}

- Nusselt number, $N u$ is defined as the non-dimensional heat transfer coefficient. It is used to measure the ratio between heat transfer by convection and heat transfer by conduction within the fluid under the same conditions.

- Reynolds number, Re means the ratio of inertia forces to viscous forces in the fluid (liquid or gas).

- Heat transfer by convection and conduction are complicated and more difficult to analyze, but most of the problems can be solved by using the combination of Nusselt number, Reynolds number and Prandtl number.

\begin{abstract}
Heat exchangers are tools used to transfer thermal energy between two fluids (liquid or gas) by convection and conduction at different level of temperatures. Heat exchangers are the common equipment and employed in many different applications because of ability to withstand high temperatures and compactness. There are no intermixing or leakage occurred between two fluids during the heat transfer process as fluids are separated by walls of heat exchanger. The main objective of this project is to determine the heat exchanger effectiveness in heat transfer performance. This will be done by investigating the performance of five different angles of heat exchanger which are 150,300, 450, 600 and 750. The effectiveness of heat exchanger depends on the convection heat transfer coefficient of the fluid. Besides that, this project also aims to develop some parameters such as Nusselt number, Reynolds number and Prandtl number for evaluating the heat transfer. It is found that the Nusselt Number at angle of 150 is lower compared to angle of 750. Meanwhile, Reynolds number for angle 150 is higher than angle 750 which means that the type of flow produced by angle 150 is turbulent flow while for 750 angle is laminar flow. Hence, the overall result of this project proved that 150 is the best angle for heat exchanger in chimney because of higher velocity, higher volume flow rate, higher density of gas and higher LMTD. The relationship between Nusselt number and Reynolds number between different angles can be observed by plotting the graph using Maple Software.
\end{abstract}

Keywords: Reynolds, Nusselt and Prandtl number, LMTD.

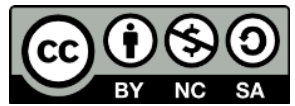




\section{INTRODUCTION}

Chimneys are channels or tubes used to convey smoke and combustion gases known as flue gases in domestic heating equipment through the roof of a building to the external environment. The chimney structure is typically arranged vertically in order to allow smooth flow of gases into the combustion part. This is called the stack effect. In order to avoid the pollution at ground level, chimneys are usually placed higher than the roof level. According to the journal by Zhang et al. (2011), chimneys consist of three major components such as the heat exchanger, the thermal chimney and the wind turbines. However, this study will only focus on the heat exchanger aspect of the chimney.

Heat exchanger is characterized as a tool used to transfer thermal energy from a fluid (liquid or gas) to another fluid or from a solid to a fluid at various temperatures in a thermal contact. Heat exchangers are used in both heating and cooling process. Plate heat exchanger is a type of heat exchanger that transfers heat between hot phase (liquid or gas) and cold phase using metal plate. It is designed to optimize heat transfer, maximize turbulence as each fluid passes, and provide the lowest life-cycle cost to unparalleled performance. Based on Ayub (2003), plate heat exchanger is commonly used in the air conditioning, heating, ventilation, and cooling industries. Plate heat exchangers are not a new phenomenon or technology in our industry. The first patent was issued in 1878 by the German inventor, Albretch Dracke before it was launched to the German company, Langem and Hundhanssen based on article by Fernandes et al. (2008).

However, this equipment was not developed commercially until 1920. Dr. Richard Seligman invented the plate heat exchanger (PHE) in 1923 and introduced the first gasketed plate heat exchanger for milk and beer as pasteurizers. A plate heat exchanger consists of several corrugated steel plates with gasketed and corner ports to obtain liquid flow composition. Through article Ayub (2003), there are still many different kinds of heat exchangers such as welded plates, compact brazed plates, semi-welded plates and frames, and shells and tube plates. But the most widely used plates in our industry are conventional gasket plate and compact brazed plate because they are geometrically similar.

According to the article by Zhang et al. (2011), the investigation was made to investigate the effect of heat transfer towards heat exchanger in chimney. The article also indicated that the parameters which affect the heat transfer rate are air velocity, surface area of the heat exchanger and the inlet air temperature. Thus, overall result of the project is that the heat transfer rate of the heat exchanger would be higher at $57{ }^{\circ} \mathrm{C}$ of inlet air temperature. Besides that, other factor that affects the effectiveness of heat exchanger is the air velocity. The report indicated that higher air velocity will cause lower effectiveness of the heat exchanger. Besides that, through observation on article from Ikegami et al. (2015), their report indicated that $65^{\circ}$ angle of heat exchanger is better in heat transfer performance. They also stated that the heat transfer performance can be found using correlation between Nusselt number and Reynolds number. However, in this project, the main objective is to evaluate the heat transfer coefficient and to determine the effectiveness of heat exchanger on chimneys using various angles $\left(15^{\circ}, 30^{\circ}, 45^{\circ}, 60^{\circ}\right.$ and $\left.75^{\circ}\right)$.

\section{Problem Statement}

A chimney is an architectural ventilation structure made of masonry, clay or metal that isolates hot toxic exhaust or household smoke generated by a boiler, stove, furnace, incinerator or fireplace. It acts by removing the fumes quickly from the room once the fire is lighted via an upward passage, called draft. In chimney, heat exchanger plays the main role to transfer heat efficiently. A heat exchanger is designed to transfer or exchange heat from fluid (a liquid or a gas) to a second fluid (another liquid or gas). By AlSammarraie \& Vafai (2017) in both cooling and heating operations, heat exchangers are used. Based on previous research by Bruno (2019), heat exchangers are commonly used in space heating, cooling, air 
conditioning, power stations, chemical plants, petrochemical plants, oil refineries, natural gas storage and treatment of wastewater.

To complete this research, a few articles have been referred. According to the article by Ikegami et al. (2015), the study was made to investigate the effect on the brazed plate heat exchanger of $65^{\circ}$ chevron angle and the pressure drop enlargement factor. The report in that article indicated that better heat transfer performance was shown by the plate heat exchanger at $65^{\circ}$ chevron angle. However, the project's main objective is to evaluate the heat transfer coefficient of condensation and the pressure drops in brazed plate heat exchangers (BHPEs) using various chevron angles.

Another article by Barasa \& Samson (2014) was published to determine the heat exchanger effectiveness. This article finds methods to recover heat lost through flue gases exhaust at the chimney stage, by taking a keen consideration of the effect of fouling especially at the core of the heat exchanger. Based on research Khalil Bassiouny et al. (2014), analytical model of heat exchanger in the chimney was developed to obtain accurate heat transfer results. So, several angles of heat exchangers $\left(15^{\circ}, 30^{\circ}, 45^{\circ}, 60^{\circ}\right.$ and $\left.75^{\circ}\right)$ are studied based on calculation of air velocity in the chimney, volume flow rate, density of gas and the logarithmic mean temperature difference (LMTD) in order to see which angle has the best outcome.

In this study, the heat transfer $(\mathrm{Q})$, overall heat transfer $(\mathrm{U})$ and convective heat transfer coefficient $(\mathrm{H})$ are calculated. The results obtained will be then develop based on the correlation of Nusselt, Reynolds and Prandtl number. Hence, the efficiency for each angle of heat exchanger can be determined.

Based on the previous studies, most researchers used CFD simulation to obtain the results related to the coefficient of heat transfer. Unfortunately, CFD simulation has expensive operational cost, time consuming and requires high-speed supercomputers. Therefore, another way to optimize the heat exchanger performance is by using theoretical formula and Maple Software. In this research, Maple has been used to plot the graph of velocity, heat transfer $(\mathrm{Q})$, overall heat transfer $(\mathrm{U})$, convective heat transfer coefficient $(\mathrm{H})$, Nusselt number and Reynolds number.

\section{METHODOLOGY}

Table (1) below shows the design parameters of heat exchanger by Barasa \& Samson (2014) which are used in calculating the overall heat transfer coefficient and heat transfer rate between different angles. There are five different angles used in this project which are $15^{\circ}, 30^{\circ}, 45^{\circ}, 60^{\circ}$ and $75^{\circ}$.

By using design parameters of the heat exchanger from Barasa \& Samson (2014), the average velocity and the temperature for air in, air out, gas in and gas out are obtained in Table 2.

Then, the area of duct must be calculated by using formula

$$
A=L x w
$$

A : Area of duct

L : length of duct

W : width of duct

The volume flow rate of air is calculated by using (1). Volume flow rate is the volume of fluid which passes per unit time.

$\mathrm{V}:$ Volume flow rate of air

$$
V=A x v
$$

A : Area of duct

$\mathrm{v}$ : velocity

Copyright@ 2021 UiTM Press. This is an open access article under the CC BY-NC-SA (https://creativecommons.org/licenses/by-nc-sa/4.0//) 
Mass flow rate of air must be calculated in order to obtain the heat transfer rate, Q. Mass flow rate is the mass of substance which passes per unit of time.

The formula for mass flow rate of air is:

Where, $\rho$ : density

$$
m=\rho A v
$$

A : area of duct

$\mathrm{v}$ : velocity

Then, from (3), the heat transfer rate can be evaluated. Heat transfer is the movement of thermal energy from one medium to another at different temperature. So, the equation of heat transfer rate, Q can be expressed as:

Q : Heat transfer rate

$$
Q=m C_{p}\left(T_{\text {out }}-T_{\text {in }}\right)
$$

$\mathrm{M}$ : Mass flow rate of water

$\mathrm{C}_{\mathrm{p}}$ : Specific heat at constant pressure

$\mathrm{T}_{\text {out }}$ : temperature of air outlet of the heat exchanger

$\mathrm{T}_{\text {in }}$ : temperature of air inlet of the heat exchanger

Noted: $\mathrm{C}_{\mathrm{p}}$ was taken at average or mean temperature

$$
\left(T_{\text {out }}-T_{\text {in }}\right)=\Delta T
$$

$\Delta T:$ Difference between temperature of air

So, it also can be writted as :

$$
Q=m C_{p} \Delta T
$$

Therefore, to find the overall heat transfer coefficient, $U$ the logarithmic mean difference temperature, LMTD must be obtained. $L M T D$ is to determine the temperature driving force for heat transfer in flow system.

The formula for $L M T D$ is :

$$
L M T D=\frac{\left(T_{h i}-T_{c o}\right)-\left(T_{h o}-T_{c i}\right)}{\ln \frac{\left(T_{h i}-T_{c o}\right)}{\left(T_{h o}-T_{c i}\right)}}
$$

Where;

$\mathrm{T}_{\text {hi }}=$ temperature hot inlet

$\mathrm{T}_{\mathrm{ho}}=$ temperature hot outlet

$\mathrm{T}_{\mathrm{ci}}=$ temperature cold inlet

$\mathrm{T}_{\mathrm{co}}=$ temperature cold outlet

$$
\begin{aligned}
& \left(T_{h i}-T_{c o}\right)=\Delta T_{a} \\
& \left(T_{h o}-T_{c i}\right)=\Delta T_{b} \\
& \text { LMTD }=\frac{\Delta T_{a}-\Delta T_{b}}{\ln \frac{\Delta T_{a}}{\Delta T_{b}}}
\end{aligned}
$$

$\Delta T_{a}$ : Temperature difference between the two streams at end $\mathrm{A}$

$\Delta T_{b}$ : Temperature difference between the two streams at end $\mathrm{B}$

Thus, by using equation (10) the heat transfer rate also can be define as

$$
Q=U A(L M T D)
$$

Then, from the equation (11), the overall heat transfer coefficient, $\mathrm{U}$ can be obtained as :

U: Overall heat transfer coefficient

$$
U=\frac{Q}{A \cdot L M T D}
$$

Q: Heat transfer rate

A: Heat transfer area

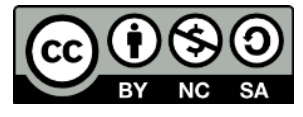


LMTD: The logarithmic mean temperature difference

The formula for heat convection is:

$$
\begin{aligned}
& Q=h A \Delta T \\
& \text { So, } Q=U A T_{l m}=h A \Delta T
\end{aligned}
$$

From equation (12) and (14) by substitution method, the overall heat transfer coefficient, $U$ can be evaluated as:

$$
\begin{aligned}
U & =\frac{h A \Delta T}{A \cdot \Delta T_{l m}} \\
U & =\mathrm{h} \\
1 & =\frac{h}{U} \\
\frac{1}{h} & =\frac{1}{U}
\end{aligned}
$$

For convective heat transfer coefficient, there are two processes which are parallel process and series process. From previous research by Ikegami et al. (2015), they stated that the heat transfer process of heat exchanger acted in series. For two or more heat transfer in series process, convective heat transfer coefficient add inversely:

$\frac{1}{h}=\frac{1}{h_{1}}+\frac{1}{h_{2}}+. .+\frac{1}{h_{n}} ;$ Where $\mathrm{n}=$ number of heat transfer involve.

Since the heat transfer rate from the hot side to the cold side across the plate wall, the plate's thickness and the thermal conductivity is considered to find the overall heat transfer coefficient $U$. The overall heat transfer coefficient is defined as the proportionality constant between the heat flux and the thermodynamic driving force for the flow of heat.

$$
\frac{1}{U}=\frac{1}{h_{c}}+\frac{1}{h_{h}}+\frac{\delta_{w}}{\lambda_{w}}
$$

$h_{c}=h_{h}$ : Equality of flow velocities in cold and hot water channels

$\delta \mathrm{w}$ : Plate's thickness

$\lambda \mathrm{w}$ : Thermal conductivity

$$
\begin{aligned}
& \frac{1}{U}-\frac{\delta_{w}}{\lambda_{w}}=\frac{1}{h_{c}}+\frac{1}{h_{h}} \\
& \frac{1}{U}-\frac{\delta_{w}}{\lambda_{w}}=\frac{2}{h}
\end{aligned}
$$

where $h=h_{c}+h_{h}$

Therefore, the convective heat transfer coefficient at the plate wall is then evaluated as:

$$
h=\frac{2}{\frac{1}{U}-\frac{\delta_{w}}{\lambda_{w}}}
$$

Convective heat transfer coefficient, $h$ is the rate of heat transfer between a solid surface and a fluid per unit surface area per unit temperature difference. Thus, the Nusselt number, Prandtl number and Reynolds number are calculated. Nusselt number is a dimensionless parameter used in heat transfer calculation between a moving fluid and solid body. It is defined as:

Nusselt number is equal to ratio between heat conduction and heat convection.

$N_{u}=\frac{Q_{\text {conv }}}{Q_{\text {conv }}}$ where

$Q_{\text {conv }}:$ Heat convection

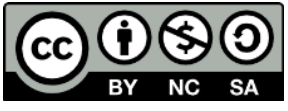

Copyright $\odot 2021$ UiTM Press. This is an open access article under the CC BY-NC-SA (https://creativecommons.org/licenses/by-nc-sa/4.0//) 
$Q_{c o n v}:$ Heat conduction

where

$$
Q_{\text {conv }}=h \Delta T
$$

h: convective heat transfer

A: Area

$\Delta T$ : difference between temperature air of in and temperature air of out

$$
Q_{\text {conv }}=\frac{R A \Delta T}{L}
$$

where

$\mathrm{R}$ : thermal conductivity of the fluid

L: length of thickness

So, it can be concluded that the equation of Nusselt number is:

$$
N_{u}=\frac{h D_{h}}{\lambda \mathrm{f}}
$$

Next, Reynolds number can be defined as the dimensionless number ratio of inertial forces to viscous forces. It is a suitable parameter for estimating the laminar or turbulent flow conditions. It is defined as:

$R e=\frac{F_{\text {in }}}{\mathrm{F}_{\text {vis }}}$ where ;

$F_{\text {in: }}$ inertia forces

$F_{\text {vis }}$ : viscous forces

where,

$$
F_{\text {in }}=\rho u D e
$$

$\rho$ : Density of gas

$\mathrm{u}$ : velocity of gas

De : diameter of pipe

where,

$$
F_{v i s}=\mu
$$

$\mu$ : kinematic viscosity

Therefore, the final equation of Reynolds number is obtained as:

$\rho$ : fluid density

$$
\operatorname{Re}=\rho u D e \mu
$$

$\mathrm{u}$ : velocity of the fluid

De: length or diameter of the fluid

$\mu$ : viscosity of fluid

\section{FINDINGS AND DISCUSSIONS}

Studies were performed based on five different angles of plate heat exchanger which are $15^{\circ}, 30^{\circ}, 45^{\circ}, 60^{\circ}$, and $75^{\circ}$. Based on this study, velocity, volume flow rate, density of gas and LMTD can be calculated from the equation that are derived. Table 3 below shows the calculation for each angle. 
Table 3: Velocity, Volume Flow Rate, Density of Gas and LMTD

\begin{tabular}{|l|l|l|l|l|l|l|l|l|}
\hline $\begin{array}{l}\text { Angle } \\
\left({ }^{\circ}\right)\end{array}$ & Tain & Tout & Tgin & Tgout & $\begin{array}{l}\text { Velocity } \\
(\mathrm{m} / \mathrm{s})\end{array}$ & $\begin{array}{l}\text { Volume Flow } \\
\text { Rate }\left(\mathrm{m}^{3} / \mathrm{s}\right)\end{array}$ & $\begin{array}{l}\text { Density of } \\
\text { gas }\left(\mathrm{kg} / \mathrm{m}^{3}\right)\end{array}$ & $\begin{array}{l}\text { LMTD } \\
\left({ }^{\circ} \mathrm{C}\right)\end{array}$ \\
\hline 15 & 22.7 & 171 & 483 & 257 & 0.70 & 0.0294 & 0.9743 & 271.2981 \\
\hline 30 & 22.7 & 184 & 483 & 256 & 0.58 & 0.02436 & 0.9743 & 264.793 \\
\hline 45 & 22.7 & 190 & 483 & 255 & 0.49 & 0.02058 & 0.9743 & 261.477 \\
\hline 60 & 22.7 & 194 & 482 & 253 & 0.395 & 0.01659 & 0.9743 & 258.076 \\
\hline 75 & 22.7 & 205 & 480 & 249 & 0.30 & 0.0126 & 0.9743 & 249.8595 \\
\hline
\end{tabular}

From this calculation, it can be assumed that the velocity decreases from $0.7 \mathrm{~m} / \mathrm{s}$ to $0.3 \mathrm{~m} / \mathrm{s}$ when the angle increases from $15^{0}$ to $75^{0}$. The volume flow rate also decreases from $0.0294 \mathrm{~m}^{3} / \mathrm{s}$ to $0.0126 \mathrm{~m}^{3} / \mathrm{s}$ when angles are increase from $15^{0}$ to $75^{\circ}$. The density of gas remains constant for each angle. The LMTD decreases from $271.2981^{\circ}$ to $249.8595^{\circ}$ when the angle increases from $15^{0}$ to $75^{0}$.

The overall heat transfer coefficient and convective heat transfer are calculated.

Table 4: R, LMTD, Q, U and H

\begin{tabular}{|l|l|l|l|l|l|l|l|l|l|}
\hline Angle $\left(^{\circ}\right.$ ) & Tain & Tout & Tgin & Tgout & R & LMTD & Q & U & H \\
\hline 15 & 22.7 & 171 & 483 & 257 & 1.5239 & 271.2981 & 4.2903 & 0.3765 & 0.7923 \\
\hline 30 & 22.7 & 184 & 483 & 256 & 1.4073 & 264.793 & 3.8703 & 0.34801 & 0.7295 \\
\hline 45 & 22.7 & 190 & 483 & 255 & 1.3628 & 261.477 & 3.3958 & 0.30921 & 0.64478 \\
\hline 60 & 22.7 & 194 & 482 & 253 & 1.3368 & 258.076 & 2.8042 & 0.26272 & 0.5357 \\
\hline 75 & 22.7 & 205 & 480 & 249 & 1.2671 & $249: 8595$ & 2.2730 & 0.2166 & 0.4459 \\
\hline
\end{tabular}

The table above shows the calculation for R, LMTD, heat transfer, overall heat transfer coefficient and convective heat transfer. $\mathrm{R}$ decreases from 1.5239 to 1.2671 as angle increase from $15^{\circ}$ to $75^{\circ}$. The heat transfer also lessen from 4.2903 to 2.2730 when the angle increases from $15^{\circ}$ to $75^{\circ}$. The overall heat transfer coefficient also decrease from 0.3765 to 0.2166 while convective heat transfer shows a decline trend from 0.7923 to 0.4459 when angles were increased from $15^{\circ}$ to $75^{\circ}$.

Table below shows the calculation of Nusselt number, Reynolds number and Prandtl number.

Table 4: Nu, Re, and $\mathrm{Pr}$

\begin{tabular}{|l|l|l|l|l|l|l|l|}
\hline Angle $\left(^{o}\right)$ & Tain & Taout & Tgin & Tgout & Nu & Re & Pr \\
\hline 15 & 22.7 & 171 & 483 & 257 & 0.0288 & 3765.88 & 0.985 \\
\hline 30 & 22.7 & 184 & 483 & 256 & 0.0312 & 3120.30 & 0.985 \\
\hline 45 & 22.7 & 190 & 483 & 255 & 0.0322 & 2636.17 & 0.985 \\
\hline 60 & 22.7 & 194 & 482 & 253 & 0.0329 & 2125.03 & 0.985 \\
\hline 75 & 22.7 & 205 & 480 & 249 & 0.03466 & 1613.95 & 0.985 \\
\hline
\end{tabular}

The table shows Nusselt number inclines from 0.0288 to 0.03466 as angle value increase. On the other hand, the Reynolds number decreases from 3765.88 to 1613.95. Prandtl number remains constant for each angle used.

After calculating using the least square method in implementation, the equation of Nusselt number for each angle is $y=8.68 x 10^{-5} x+0.028$. Then, the graph below can be generated from the equation. 


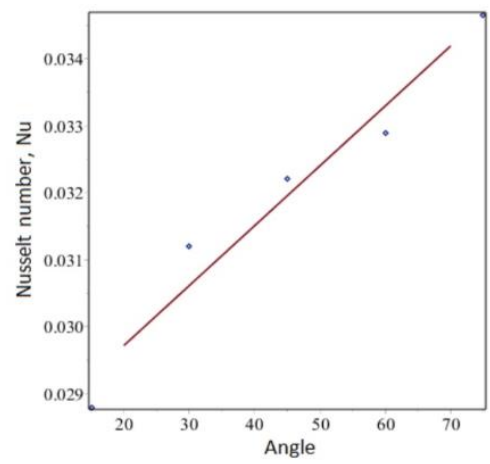

Figure 1: Relationship between each angle with the Nusselt number

Next, the equation of Reynolds number for each angle is $y=-35.328 x+4242.026$. Then, the graph below can be generated from the equation.

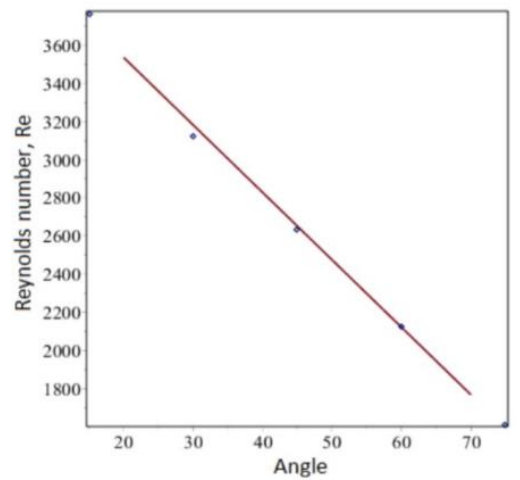

Figure 2: Relationship between each angle with the Reynolds number.

Table 5: Heat Transfer Coefficient, U

\begin{tabular}{|l|l|l|}
\hline Angle & $\mathbf{Q}$ & $\mathbf{U}$ \\
\hline 15 & 4.2903 & 0.3765 \\
\hline 30 & 3.8703 & 0.34801 \\
\hline 45 & 3.3958 & 0.30921 \\
\hline 60 & 2.8042 & 0.26272 \\
\hline 75 & 2.2730 & 0.2166 \\
\hline
\end{tabular}

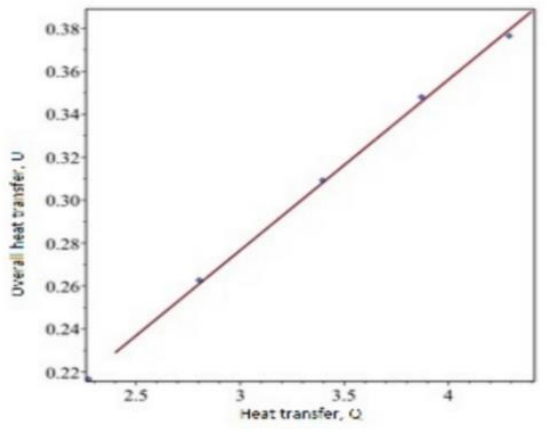

Figure 3: Heat Transfer, $Q$ vs Overall Heat transfer Coefficient, $U$

Figure 3 shows that higher heat transfer resulted in higher overall heat transfer coefficients. So, angle $15^{0}$ has the highest heat transfer and overall heat transfer coefficients. 
Table 6: Velocity, $V$ vs Overall Heat Transfer Coefficient, $U$

\begin{tabular}{|l|l|l|}
\hline Angle & Velocity(m/s) & $\mathbf{U}$ \\
\hline 15 & 0.70 & 0.3765 \\
\hline 30 & 0.58 & 0.34801 \\
\hline 45 & 0.49 & 0.30921 \\
\hline 60 & 0.395 & 0.26272 \\
\hline 75 & 0.30 & 0.2166 \\
\hline
\end{tabular}

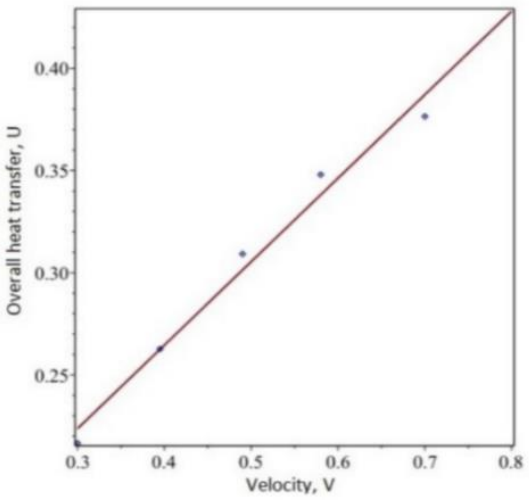

Figure 4: Velocity, V vs Overall Heat transfer Coefficient, $U$

Figure 4 shows that higher velocity resulted in higher overall heat transfer coefficients. So, the $15^{0}$ is the highest velocity and overall heat transfer coefficients. Table and graph below shows the volume flow rate versus heat transfer.

Table 7: Volume Flow Rate vs Heat Transfer, $Q$

\begin{tabular}{|l|l|l|}
\hline Angle & Volume Flow Rate $\left(\mathrm{m}^{3} / \mathbf{s}\right)$ & $\mathbf{Q}$ \\
\hline 15 & 0.0294 & 4.2903 \\
\hline 30 & 0.02436 & 3.8703 \\
\hline 45 & 0.02058 & 3.3958 \\
\hline 60 & 0.01659 & 2.8042 \\
\hline 75 & 0.0126 & 2.2730 \\
\hline
\end{tabular}

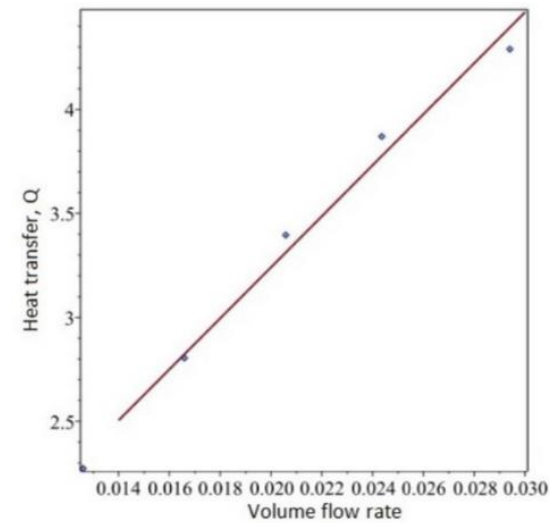

Figure 5: Volume Flow Rate vs Heat Transfer, $Q$

The graph shows that higher volume flow rate resulted in higher heat transfer. So, the $15^{0}$ is the best volume flow rate and heat transfer. Next, the graph for convective heat transfer and overall heat transfer is developed. 
Table 8: Convective Heat Transfer Coefficient, $H$ vs Overall Heat Transfer Coefficient, U

\begin{tabular}{|l|l|l|}
\hline Angle & $\mathbf{H}$ & $\mathbf{U}$ \\
\hline 15 & 0.7923 & 0.3765 \\
\hline 30 & 0.7295 & 0.34801 \\
\hline 45 & 0.64478 & 0.30921 \\
\hline 60 & 0.5357 & 0.26272 \\
\hline 75 & 0.4459 & 0.2166 \\
\hline
\end{tabular}

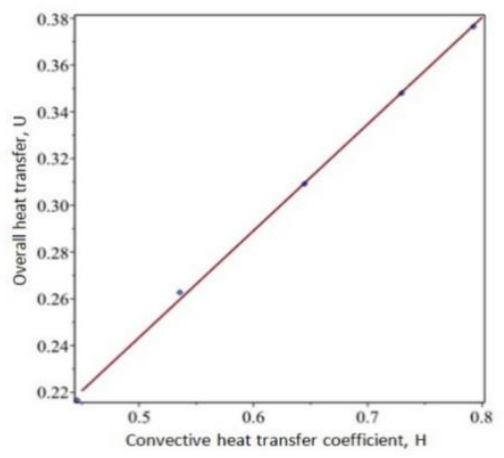

Figure 6: Convective heat Transfer Coefficient, $H$ vs Overall Heat transfer Coefficient, $U$

The graph shows that higher convective heat transfer resulted in higher overall heat transfer coefficient. So, the $15^{0}$ is the highest convective heat transfer and overall heat transfer coefficients. Thus, the graph for Reynolds number versus Nusselt number is developed.

Table 8: Reynolds Number vs Nusselt Number

\begin{tabular}{|l|l|l|}
\hline Angle & Re & Nu \\
\hline 15 & 3765.88 & 0.0288 \\
\hline 30 & 3120.30 & 0.0312 \\
\hline 45 & 2636.17 & 0.0322 \\
\hline 60 & 2125.03 & 0.0329 \\
\hline
\end{tabular}

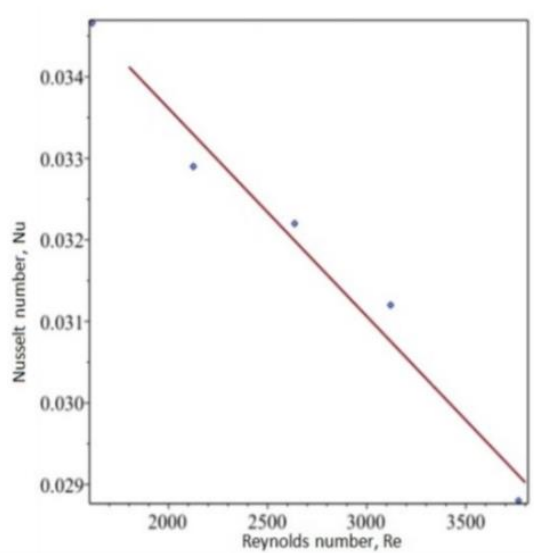

Figure 7: Reynolds Number, Re vs Nusselt Number, $\mathrm{Nu}$

The graph shows that higher Reynolds number resulted in lower Nusselt number. 
Table 9: Reynolds Number vs Nusselt Number

\begin{tabular}{|l|l|l|}
\hline Angle & Re & In Nu \\
\hline 15 & 3765.88 & 3.547 \\
\hline 30 & 3120.30 & 3.467 \\
\hline 45 & 2636.17 & 3.436 \\
\hline 60 & 2125.03 & 3.414 \\
\hline 75 & 1613.95 & 3.362 \\
\hline
\end{tabular}

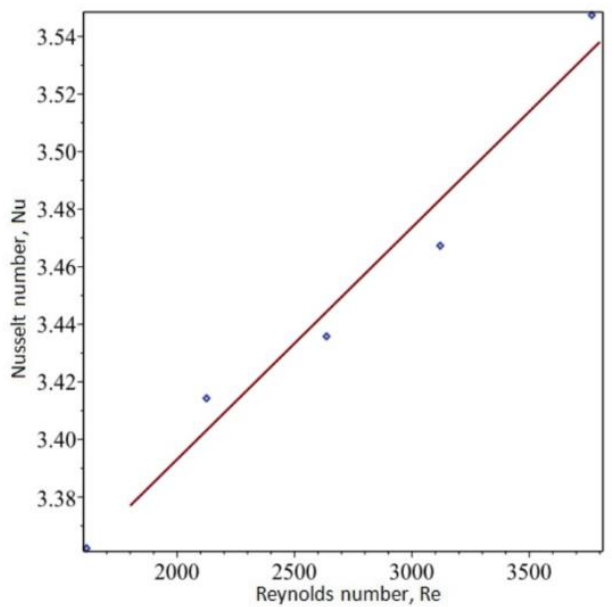

Figure 8: Reynolds Number, Re vs Nusselt Number, Nu

The graph shows that higher Reynolds number resulted in higher Nusselt number.

\section{CONCLUSION AND RECOMMENDATIONS}

The main objective of this study is to find the best angle that can be used in the heat exchanger. From study by Ny et al. (2016), it can be concluded that increasing Reynolds number resulting in increase of Nusselt numbers. Previous study by Ayani (2016) stated that, Reynolds number increment is related to higher velocity. Higher Reynolds number leads to increase in Nusselt number then lead to the higher heat transfer. Therefore, based on the experiment by Premkumar, Swaminadhan and Rao (2016), the result showed that when the mass flow rate increases, the heat transfer coefficient also increases. Therefore, the increase in the amount of Reynolds therefore triggered the rise in the general heat transfer coefficient. Other than that, the number of Nusselt also increase with the increase in the number of Reynolds due to higher flow rates in the channel. So, from previous research, it can be concluded that higher velocity means higher mass flow rate which leads to higher heat transfer hence higher the overall heat transfer coefficient.

The present result shows that $15^{0}$ is the best angle for the plate heat exchanger because it has higher velocity, higher volume flow rate, higher density of gas, and higher LMTD. This results in higher overall heat transfer coefficient and also higher in convective heat transfer. It will then be contributed to the higher Reynolds number and Nusselt number. Based on these outcomes, the objectives of this study were completed, and each graph can be plotted by using Maple software. In conclusion, the project findings suggest that the use of suitable software is the most important aspect needed to optimize the heat transfer performance. The use of CFD simulation in the project will enable the researchers to obtain better and more accurate results in the future. 


\section{REFERENCES}

Al-Sammarraie, A. T., \& Vafai, K. (2017, Aug). Heat transfer augmentation through convergence angles in a pipe. Numerical Heat Transfer Part A - Applications, 72(3),197-214. Doi : $10.1080 / 10407782.2017 .1372670$

Ayani, M. B. (2016). Numerical Investigation of the Effect of Geometrical Shape of Plate Heat Exchangers on Heat Transfer Efficiency. International Journal of Mechanical, Aerospace, Industrial, Mechatronic and Manufacturing Engineering, 10, 872-876. Retrieved from https://www.researchgate.net/publication/ 324026378

Ayub, Z. H. (2003, sep). Plate heat exchanger literature survey and new heat transfer and pressure drop correlations for refrigerant evaporators. Heat Transfer Engineering, 24(5), 3-16. doi: $10.1080 / 01457630304056$

Ayub, Z. H., Ayub, A. H., Ribatski, G., Moreira, T. A., \& Khan, T. S. (2017). Two-phase pressure drop and flow boiling heat transfer in an enhanced dimpled tube with a solid round rod insert. International Journal of Refrigeration, 75(C), 1-13. doi: 10.1016/ j.ijrefrig.2017.01.008

Barasa, W. A., \& Samson, K. (2014). Designing a boiler chimney heat recovery system against fouling. Journal of Department of Mechanical and Manufacturing Engineering, 6, 165-199. Retrieved from http://www.novapdf.com

Fernandes, C. S., Dias, R. P., Nóbrega, J. M., \& Maia, J. M. (2008). Friction factors of power-law fluids in chevron-type plate heat exchangers. Journal of Food Engineering, 89(4), 441 - 447. doi: https://doi.org/10.1016/ j.jfoodeng.2008.05.022

Ikegami, Y., Mutair, S., \& Kawabata, Y. (2015, mar). Experimental and Numerical Investigations on PlateType Heat Exchanger Performance. Open Journal of Fluid Dynamics, 05(01), 92-98. doi: 10.4236/ojfd.2015.51011

Premkumar, S.D., Swaminadhan, P. \& Rao, B. S. (2016). Optimization of corrugation angle for the heat transfer performance of corrugated plate heat exchangers. International Research Journal of Engineering and Technology (IRJET), 03, 924-929. Retrieved from https://pdfs.semanticscholar.org

Zhang, D., Yang, Y., Pan, M., \& Gao, Z. (2011). Toward a heat recovery Chimney. Sustainability, 3(11), 2115-2128. doi: 10.3390/su3112115 